\title{
Design and Development of Press Tool Changing Attachment on Automated Guided Vehicle
}

\author{
A. Panchal ${ }^{1 *}$, B. Salunkhe ${ }^{2}$, R. Patil ${ }^{3}$ \\ ${ }^{1,2,3}$ G. H. Raisoni Institute of Engineering and Management, Jalgaon, India \\ \{avi30panchal@gmail.com\}
}

\begin{abstract}
In the present work, a hydraulic scissors lift is developed to lift up to $300 \mathrm{~kg}$ load at a height of around one meter. This mechanism is specially designed for loading and unloading press tool dies by considering press machine shop where installation of Gantry cranes and use of forklift is not convenient. A simple attachment is also provided for pulling the die from bolster plate to the scissor lift platform. This whole arrangement is mounted on AGV. The objective of the present work is to design and develop a press tool changing attachment with minimum material, minimum overall cost and significant strength. Design calculations must not be exceeded standards, allowable maximum deflection and stresses. To analyze and validate manual calculations, solid modeling and computer simulations are involved using CATIA v5 R19 and Hypermesh 11.0 softwares. Number of linear static FEA analyses has done to get accurate results. From the results we can say that deflection is still in the acceptable range. The research highlights to reduce total idle time of press machine while die changing operation results in increased production rate. Number of trials are taken on the same model in press machine shop. Total time required for changing and remounting the die is reduced by approximately half an hour compared to existing method of press tool changing.
\end{abstract}

\section{Key words: Lift design, Solid Model, Design of hydraulic drives, Hyper mesh, Idle time reduced}

\section{Introduction}

Scissors lifts are used for several applications within industrial and day today world. They have now become excellent choice whenever workers, materials or machine components need to be raised above ground level. Scissor lifts may powered by gear mechanism, pneumatic drives or hydraulic drives. Properties of hydraulic system decide high efficiency, security in operation as well as stability under different working conditions. This work deals with the design of the press tool changing attachment in the form of scissor lift mounted on AGV (Automated Guided Vehicle) and its manufacturing along with the performance analysis of major components. Functional objective of the proposed model is loading, unloading and transportation of the press tool dies in short time. It helps in saving the time as in manual handling. Also reducing the idle time of press machine while loading, unloading of dies. Major requirement of press shop is to reduce the total idle time of machine and increase production rate. The displacement of platform is done by the application of force of hydraulic actuators. This force causes expansion of the cross pattern (scissor up and down). Retraction of hydraulic cylinder is achieved when lowering of platform is required. Design of Scissor lifter has been done for each and every component with design standards accepted worldwide and with the factor of safety 1.5. Designed data has taken to prepare a CAD model in one of the user friendly and mostly used modelling software that is CATIA v5 R19. To analyse the results of theoretical calculations, Hypermesh software is used which is well known for simulation and validation of designed parameters. Tetra meshing of size 3 is taken for further discretization and application of boundary conditions and loads. Solution of simulated results is in the form of Von-Mises stresses and displacement. Fabrication of the working model of hydraulic scissor lift is done in mechanical workshop. Then it is tested for the changing different dies of press machine. Performance at a time of testing is appreciable and fulfils all requirements.

B. Iyer, S. Nalbalwar and R. Pawade (Eds.)

ICCASP/ICMMD-2016. Advances in Intelligent Systems Research.

Vol. 137, Pp. 171-175.

(c) 2017. The authors - Published by Atlantis Press

This is an open access article under the CC BY-NC license (http://creativecommons.org/licens)es/by-nc/4.0/). 


\section{Literature Review}

Divyesh P. Ubale focuses on various aspects related to lifting mechanism and its design. The portable platform for work material is operated by hydraulic cylinder which is powered by an electric motor. In this paper, we have carried out detailed analysis of scissor members against bending and buckling failure and also focused on several design aspects and working and performance of scissor lifter mechanism [5]. On another paper designs a long-travel material transport system for a unit load AGV. A push pull load-transfer mechanism is then designed to pick up and down the pallet in both sides, including a lifting module that changes the vertical height of the platform and a translational module that moves their convex blocks in the lateral direction [2]. Arturo Valencia et al designed a lift platform sustained through a dual system of support scissor arms in its lower part, which offers the mechanical, upward and downward motion in a vertical plane and on a base frame. This in its turn is actuated by a hydraulic mechanism. The lift platform is characterised in such a way that, it operates on electronic as well as automatic control system. Also it includes hydraulic unit for the movement of mobile arms [3].

\section{Material Selection}

After thorough survey of the strength and economical study of different materials, it is found that mild steel (MS) is the most appropriate material for the construction of the unit. Also Stainless Steel (SS) is used at top of platform for support and to have better appearance. Also Stainless Steel sheet of $5 \mathrm{~mm}$ thickness is used at top as material for easier movement of die over the platform.

\section{Design}

\subsection{Basic Dimensions Of member}

Lift Extension

At maximum extension, an " $X$ " arrangement of the lift moves $0.9 \mathrm{~m}=900 \mathrm{~mm}$.

- $\quad$ Length of base $=850 \mathrm{~mm}$

- Width of base $=450 \mathrm{~mm}$

- Height of base from ground $=500 \mathrm{~mm}$ (Assumed of AGV)

- At maximum extension, Angle of inclination = $50 \mathrm{deg}$

- At maximum extension, distance between two scissors feet $=600 \mathrm{~mm}$

- Distance moved by sliding foot to full extension $=400 \mathrm{~mm}$

Bearings

- $\quad$ Number of ball bearings $=4$

- Number of shell bearings $=36$

- Internal diameter of ball bearings $=17 \mathrm{~mm}$

- Internal diameter of shell bearings $=11 \mathrm{~mm}$

- External diameter of ball bearings $=32 \mathrm{~mm}$

- External diameter of shell bearings $=15 \mathrm{~mm}$

- $\quad$ Pivot pin diameter $=10 . .6 \mathrm{~mm}$

Platform

- Total length of platform $=850 \mathrm{~mm}$.

- Total width of plat form $=450 \mathrm{~mm}$

- $\quad$ Total height of platform $=500 \mathrm{~mm}$

Permissible load on plat form + platform weight $=300 \mathrm{~kg}=2.94 \mathrm{KN}$

Jointed Members: $\quad$ Thickness of cylindrical pipe $=3 \mathrm{~mm}$ 
Table 1 Bending moment on arm for changing $\theta$

\begin{tabular}{|l|l|l|}
\hline $\begin{array}{l}\text { Case } \\
\text { No. }\end{array}$ & $\begin{array}{l}\text { Angle of } \\
\text { inclination } \\
\text { of scissors } \\
\text { arm }(\theta)\end{array}$ & $\begin{array}{l}\text { Bending moment } \\
\text { N-m }\end{array}$ \\
\hline I & $\theta=10^{0}$ & $1744 \mathrm{Nm}$ \\
\hline II & $\theta=20^{0}$ & $1664.99 \mathrm{Nm}$ \\
\hline III & $\theta=30^{0}$ & $1357.23 \mathrm{Nm}$ \\
\hline IV & $\theta=40^{0}$ & $1534.43 \mathrm{Nm}$ \\
\hline V & $\theta=50^{\circ}$ & $1138.91 \mathrm{Nm}$ \\
\hline
\end{tabular}

Table 2 Components and its weights

\begin{tabular}{|l|l|l|l|}
\hline Name & Qty & $\begin{array}{l}\text { Mass of } \\
\text { each }\end{array}$ & $\begin{array}{l}\text { Total } \\
\text { mass }\end{array}$ \\
\hline Arm & 04 & $5.4 \mathrm{Kg}$ & 21.6 \\
\hline Angle 850x50x5 & 04 & $3 \mathrm{Kg}$ & 12 \\
\hline Angle 450x50x5 & 04 & $1.5 \mathrm{Kg}$ & 06 \\
\hline Hyd Cylinder (Lifting) & 02 & $11 \mathrm{Kg}$ & 22 \\
\hline Wheels & 04 & $0.13 \mathrm{Kg}$ & 0.52 \\
\hline Top Plate & 01 & $09 \mathrm{Kg}$ & 09 \\
\hline Hinge Bkt & 04 & $0.4 \mathrm{Kg}$ & 1.6 \\
\hline Bearings & 08 & $0.02 \mathrm{Kg}$ & 0.16 \\
\hline Guide Frame & 01 & $4.1 \mathrm{Kg}$ & 4.1 \\
\hline Pin & 15 & $0.060 \mathrm{Kg}$ & 0.9 \\
\hline Hyd Cyl. (Pull) & 01 & $15 \mathrm{Kg}$ & 15 \\
\hline Total & & $92.88 \mathrm{~kg}$ & \\
\hline
\end{tabular}

From the above analysis, the maximum bending moment $=1744.92 \mathrm{~N}-\mathrm{m}$ occurs at the point when $\theta=10^{\circ}$. Therefore, smaller the angle, higher the bending moment and vise-versa.

\subsection{Model of Scissor Lift}

A CAD model is prepared on the modelling software CATIA v5 R19. It is the assembly of various components listed in Table 2 and Figure 1.

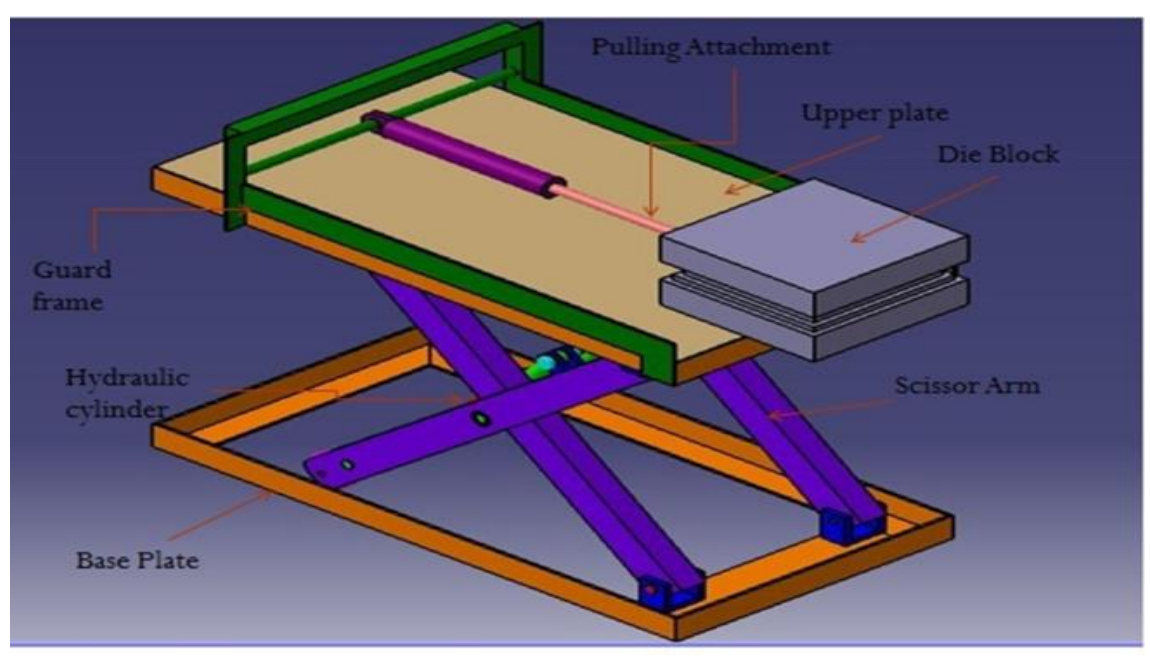

Fig. 1. Model of Scissor Lift.

\subsection{Finite Element Analysis}

It is a numerical technique for finding approximate solutions to boundary value problems such as structural analysis, electromagnetic analysis, computational fluid dynamics, thermal analysis etc. CAD model is constructed in CATIA v5 R19; it is then imported in Hypermesh 11.0 for structural analysis of scissor lift. In 
hypermesh, first we meshed the component and given boundry conditions as well as load conditions precisely. Then gone for solution and at the end for hyperview. Results obtained are as follows.

\subsection{Results of Simulation}
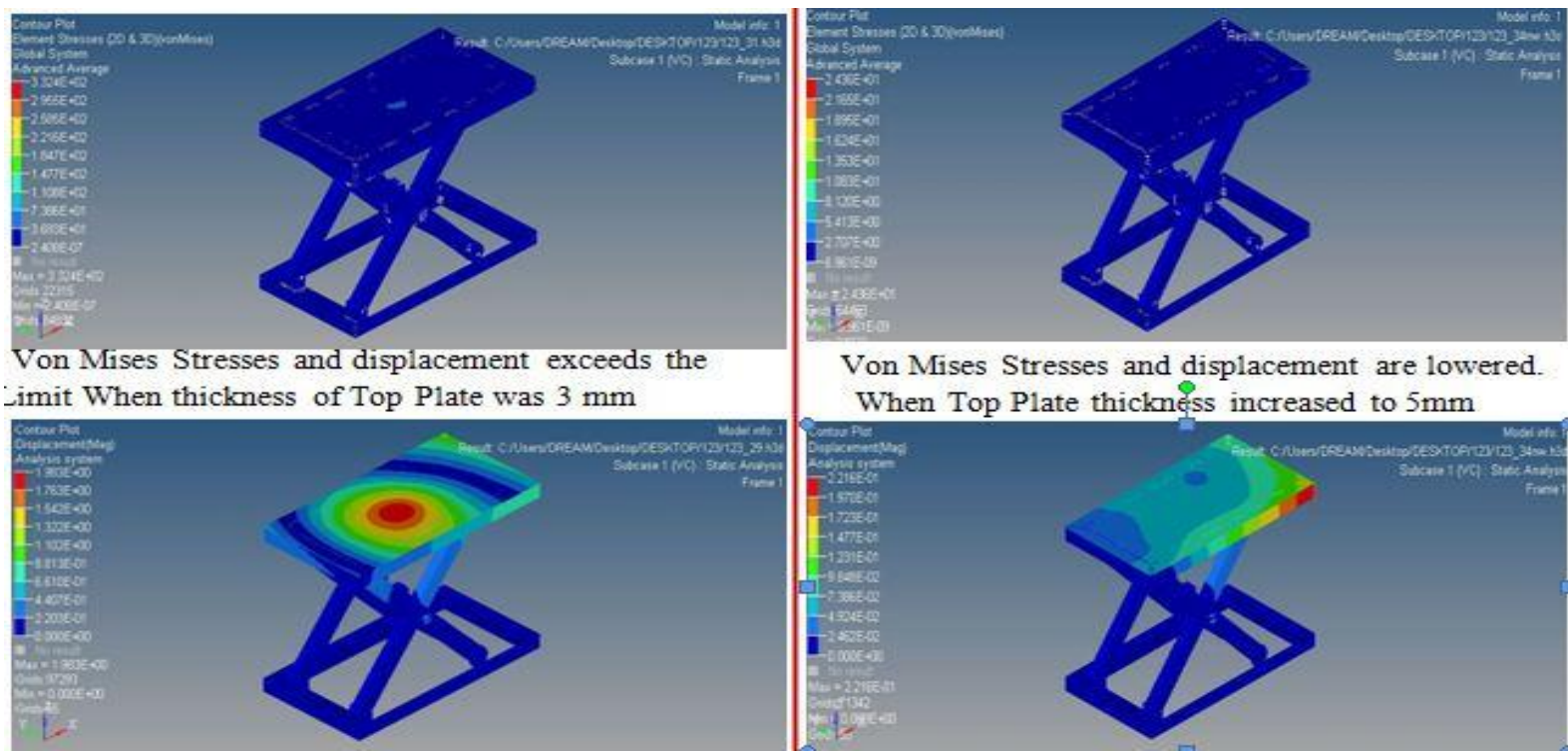

Von Mises Stresses and displacement are lowered. When Top Plate thickness increased to $5 \mathrm{~mm}$

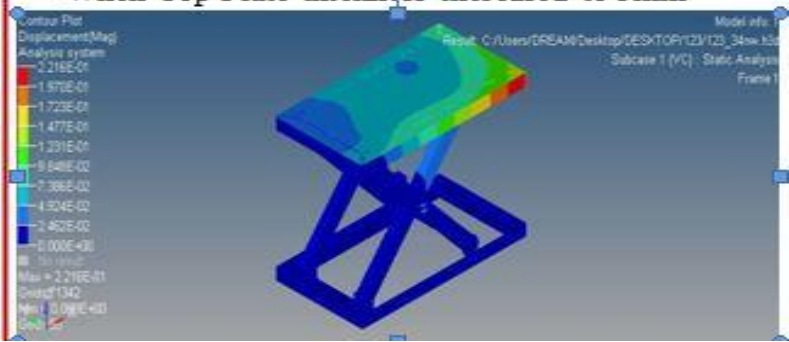

Fig. 2. Von-Mises stresses and total displacement

Results of Von-Mises stresses and total displacement are obtained from software first was failed then optimization gives desired results in second section of Figure3.

Table 3 FEA results under static loading

\begin{tabular}{|c|c|c|c|c|c|}
\hline \multirow{2}{*}{$\begin{array}{c}\text { Sr. } \\
\text { No. }\end{array}$} & Component & \multicolumn{2}{|c|}{ Von-Mises stresses (MPa) } & \multicolumn{2}{|c|}{ Displacement/ Deflection (mm) } \\
\cline { 3 - 6 } & & Min. & Max. & Min. & Max. \\
\hline 1 & Arm & 0.00 & 98.239 & 0.012 & 0.217 \\
\hline 2 & Platform & 0.00 & 123.346 & 0.001 & 1.380 \\
\hline
\end{tabular}

Results indicate Von-Mises stress below yield strength of the material, which satisfies the design and deflection was about $1.98 \mathrm{~mm}$. Modification of design is carried out to reduce deflection of structure below $0.21 \mathrm{~mm}$, Table 3 .

\section{Results and Discussion}

- Both theoretical and analytical results are approximately same. Our Design meeting the required standards

- Developed model is tested for changing and remounting the dies. During the test overall time is also counted and compared with the existing manual handling, Table 4. 
Table 4 Comparison of overall time required to change the press tool die by developed system with existing one.

\begin{tabular}{|c|c|c|c|c|}
\hline $\begin{array}{c}\text { Sr. } \\
\text { No. }\end{array}$ & Weight of die & $\begin{array}{c}\text { By existing manual } \\
\text { handling (Time) }\end{array}$ & $\begin{array}{c}\text { By scissor lift on } \\
\text { AGV (Time) }\end{array}$ & Time saved \\
\hline 1 & Up to $100 \mathrm{Kg}$ & $25 \mathrm{~min}$ & $4 \mathrm{~min}$ & $21 \mathrm{~min}$ \\
\hline 2 & Up to $300 \mathrm{Kg}$ & $35 \mathrm{~min}$ & $5 \mathrm{~min}$ & $31 \mathrm{~min}$ \\
\hline
\end{tabular}

\section{Conclusions}

- Total idle time of press machine is decreased by half an hour per cycle of die changing

- Performance at a time of testing is appreciable and fulfils all objectives

- Theoretical calculations are done with static condition of scissor lifter considering maximum efficiency of hydraulic actuator

- From the results we can say that deflection is still in the acceptable range

\section{References}

[1] Hongyu, Tian, and Zhang Ziyi. "Design and simulation based on Pro/E for a hydraulic lift platform in scissors type." Procedia Engineering 16 (2011): 772-781.

[2] Wu, Xing, et al. "Design and control of material transport system for automated guided vehicle." Control (CONTROL), 2012 UKACC International Conference on. IEEE, 2012.

[3] Lei, Huang, Yuan Genfu, and Chen Xuehui. "Simulation analysis of certain hydraulic lifting appliance under different working conditions." Physics Procedia 25 (2012): 2268-2275.

[4] Ochoa, Arturo Valencia, and Jaime Antonio Uribe Uribe. "Scissors lift platform with electronic control." U.S. Patent No. 5,695,173. 9 Dec. 1997.

[5] Ubale, Divyesh Prafulla, Alan Francy, and N. P. Sherje. "Design, Analysis and Development of Multiutility home equipment using Scissor Lift Mechanism." (2015): 2405-2408.

[6] Rashid, Helmi, et al. "Design Review of Scissors Lifts Structure for Commercial Aircraft Ground Support Equipment using Finite Element Analysis." Procedia Engineering 41 (2012): 1696-1701.

[7] Tabie, Vitus M., and Yesuenyeagbe AK Fiagbe. "Weight Optimization Of A Lift-Tipping Mechanism For Small Solid Waste Collection Truck." 